\title{
Repairing spinal roots after brachial plexus injuries
}

\author{
MA Glasby ${ }^{1}$ and TEJ Hems ${ }^{2}$ \\ ${ }^{1}$ Department of Anatomy, University of Edinburgh Medical School, Teviot Place, Edinburgh EH8 9AG; \\ ${ }^{2}$ Nuffield Orthopaedic Centre, Headington, Oxford, UK
}

The problems of repairing spinal roots after brachial plexus avulsion injuries are discussed in the light of current surgical diagnosis and treatment. An advancing understanding of the cellular mechanisms of nerve regeneration and progress in surgical technology indicates a possibility for the repair at least of ventral roots with grafts which may be of neural or non-neural origin. Enhancement of the regenerative properties may further be made possible by the application of neurotrophic factors at the repair site or centrally. The short and long-term implications of current research into these methods are discussed.

Keywords: spinal root repair; nerve regeneration; ventral root implantation; neurotrophic factors

\section{The present}

Over 350 patients suffer severe damage from closed traction injuries of the brachial plexus each year in the United Kingdom. ${ }^{1}$ Many of these are young adults involved in motorcycle accidents. ${ }^{2}$ Over recent years, surgical exploration has been increasingly recommended if the mechanism of injury suggests that a major disruption is likely and if examination reveals a complete absence of function of all or any part of the plexus. ${ }^{1,3-5}$ Operation should be carried out as soon as possible after injury.

For the individual patient preoperative investigations are directed at distinguishing between pre- and postganglionic lesions. ${ }^{6} \mathrm{CT}$ scanning with contrast enhancement is probably the best investigation, but no method is $100 \%$ accurate. ${ }^{7}$

At operation it is important to explore the whole plexus since lesions can occur at any level. Nerve ruptures are required with conventional nerve autografts or with a vascularised ulnar nerve graft if the C8 and $\mathrm{T} 1$ roots are irreparably damaged. ${ }^{4,5}$ At present pre-ganglionic damage is not thought to be amenable to repair. However useful function can be restored to some muscles using nerve transfers (neurotisation) from the accessory nerve, cervical plexus or intercostal nerves. ${ }^{8}$ These transfers appear to have the added bonus of relief of pain in many patients.

Results from these procedures are better if repair is carried out within 3 months of injury. If surgery is performed within days of injury, before Wallerian degeneration has occurred, intraoperative electrophysiological testing allows recognition of the predominantly motor bundles of the major nerves, thus facilitating appropriate connection of grafts and transfers. Repair of ruptures within the posterior triangle will achieve worthwhile function of the shoulder and elbow in $60 \%$ of patients. Useful function of the hand is rarely regained in adults but appears to have a slightly better prognosis in young children. ${ }^{4,5}$

\section{The future}

The typical traction injury sustained by any spinal root consists of rupture of all neural elements whilst the integrity of the fibrous epineurium is maintained (Sunderland type IV). ${ }^{9}$ Repair is by excision of the damaged segment and interposition of a nerve autograft between the two nerve ends. Normal nerve anatomy at least in the macroscopic sense must be identified at each nerve end and this usually means that relatively long nerve grafts are required. ${ }^{5}$ Technically long grafts offer no particular problems but the eventual success of any nerve grafting technique is inversely proportional to graft length. In the future it may be possible to increase the speed of regeneration by the use of nerve cell rescue factors ${ }^{10}$ but the ultimate problem is one of increasing the specificity of regeneration so that individual pioneering axons become chemically directed to their proper end organs as they traverse the inevitable geometrical chaos imposed by the repair site.

A further factor which must affect the eventual outcome of any nerve repair is the stretch reflex. ${ }^{11,12}$ Even when after nerve repair, good motor power and protective sensation have been restored, the patient still complains of poor coordination. It is statistically highly unlikely that any monosynaptic reflex arc will be restored after nerve injury and repair and this must be expected to have a serious effect upon the servo control of movement. Barker ${ }^{13,14}$ in his elegant experiments on muscle receptor reinnervation has demonstrated that both muscle spindles and Golgi tendon organs can become reinnervated with each other's homonymous 
nerve fibres and since these receptors signal quite opposite information about muscle movement, the likelihood of reestablishing useful proprioceptive control is remote.

At present there are really no options available to the surgeon for treating avulsed spinal roots. ${ }^{15}$ The theoretical possibility of reimplanting avulsed spinal roots was recognised in the first years of this century by Basil Kilvington ${ }^{16,17}$ whose very considerable body of work on peripheral nerve repair has been largely forgotten, only to be rediscovered by others. Kilvington's goal was reinnervation of the bladder after spinal cord injury by the rerouting of functioning but unimportant spinal motor roots originating above the lesion into the distal processes of nerves from below the transection. This goal still remains to be achieved.

In brachial plexus injuries, there has been a resurgence of interest in the reimplantation of motor roots after avulsion injury. The nature of the injury may vary in each case but there is a strong probability that some motoneuron cell bodies remain intact in the anterior grey horn of the injured spinal segment. Theoretically axons may regenerate out of the spinal cord into ventral roots if these are repaired. The environment of the peripheral nervous system is able to support regeneration and there is no reason why fibres should not grow distally and reinnervate target muscles, as occurs after repair of any peripheral nerve. The appropriateness of the environment is all-important and implies a similarity to peripheral nerve containing Schwann cells and basement membrane rich in neurotrophic and neurotopic matrix proteins rather than the central nervous system environment which has been shown to inhibit neurite regrowth. Functional recovery after repair of dorsal roots is not possible, at least in adult animals, as this would require the central processes of peripheral sensory neurons to regenerate into the CNS and make connections. However, reinnervation of the cord from dorsal roots may be possible in neonates.

Early work by Bonney ${ }^{15}$ and Jamieson and Eames ${ }^{18}$ supported this theoretical possibility. These workers undertook some preliminary studies which indicated the possibility of useful repair of ventral but not dorsal spinal roots in dogs. In 1977 a single human case showed that the operation was technically possible and produced no harmful effects but unfortunately no recovery was seen. As a result of this important early work a number of points were identified. These have set the scene for future experimental and clinical work. Because torn spinal roots become rapidly fixed to distal structures, it is possible to contemplate successful reattachment only in the first $48 \mathrm{~h}$ at most. There is always a risk of operating on or near a spinal cord already damaged by the injury and this is increased by the need to rotate the cord to reach the ventral roots. Rotation for short periods of time has, however, been found to be possible and not associated with harmful effects. The rootlets are very delicate structures and do not tolerate surgical manipulation well. However, modern neurosurgical techniques may overcome this problem. Finally, it is probably vain to attempt to repair the dorsal roots because their central processes supported by oligodendrocytes are unable to regenerate. However one of the interesting possibilities suggested by in vitro studies is that of blocking the inhibitory tendencies of these cells by means of specific antibodies. Today two major groups are involved in the experimental evaluation of motor root repair and one of these groups has a very limited human clinical experience. In Edinburgh, Glasby and Hems have used freeze-thawed muscle autografts to bridge the short defect between the anterior grey horn of the spinal cord and the motor root of mixed peripheral nerves contributing to the brachial plexus and the cauda equina. The experimental animal has been the sheep. Successful motor reinnervation was demonstrated by these workers after transection and after avulsing the ventral roots. ${ }^{19-21}$ In Stockholm, Carlstedt and colleagues have performed similar operations in primates in which the avulsed ventral roots have been reimplanted into the anterior funiculus of the spinal cord directly. ${ }^{22-24}$ There was a clear and significant reinnervation of muscles supplied by the injured segment that had shown total denervation immediately after injury. In a single human case, Carlstedt et al (personal communication) used sural nerve grafts to effect the intradural repair of motor nerve roots of the brachial plexus injured by severe traction. Within 3 years these workers observed recovery of function in all of the muscles supplied by the damaged roots with the exception of the intrinsic muscles of the hand. This important case indicates that surgery was effective in the recovery of function. However the whole issue clearly needs more extensive evaluation both clinically and in the research laboratory.

The question of whether a role exists for nerve growth factors in surgical nerve repair remains to be answered. These factors, perhaps more accurately described as 'nerve cell rescue factors' have variously been shown to enhance nerve cell growth in vitro and some dramatic claims and predictions have been made by individuals clearly unfamiliar with the practicalities of treating nerve injuries. It seems likely that these substances might, if used appropriately, have a great deal to offer in enhancing the regenerative capacity of injured nerves. ${ }^{10,25}$ However at present there is no clear evidence that any particular factor is of immediate use in the clinical situation or in any realistic model of the clinical situation. The reason for this is that, besides the need to demonstrate an effectiveness in making cells grow, for these factors to be clinically useful, they must be shown to be capable of localised delivery at the appropriate site over an appropriate time period after nerve injury and at an appropriate and maintained concentration. These somewhat obvious and practical points do not yet appear to have captured the imagination of researchers in the field but must be central to any application of their more fundamental findings.

Ciliary neurotrophic factor (CNTF) which is present in Schwann cells, has been shown spcifically to rescue motoneurons in vitro and at present CNTF seems a likely candidate for clinical use. ${ }^{26}$ It will be of interest 
to see how this and other growth factors may be used first in animal models and eventually in patients.

Recent experiments in the rat have indicated that a combination of growth enhancement or cell rescue may be combined with suppression of the chemical mediators which inhibit nerve cell regeneration in the central nervous system. ${ }^{27-29}$ Such a situation, by providing a peripheral nervous system environment in the spinal cord, would theoretically open up a potential for regeneration to take place both into and out of the neural axis. However it must be remembered that the initiation of regeneration is but a small part of the whole process with specificity remaining the as yet unattainable determinant of success. Enhancing the rate and extent of regeneration still depends upon capacity to make proper connections and indeed may, because of the greater numbers of regenerating fibres, increase chaos and 'miswiring' rather than improving the result. The process will remain one governed by statistical probability until some means of increasing specificity of 'rewiring' is achieved.

It is important, therefore, to recognise that whereas this new and very fundamental avenue of research must be vigorously pursued, it is unlikely to be of benefit to patients for a very long time and it would be improper and ungenerous to raise hopes at this early stage. In the shorter term surgical reconstructive procedures such as those described above, though themselves still in their infancy, would seem to offer a more realistic prospect for patients with these devastating injuries. Further research in the laboratory into root reimplantation seems both justified and urgently needed. Kilvington's goal is as important today as it ever was.

\section{References}

1 Birch R. Advances in diagnosis and treatment in closed traction lesion of the supraclavicular brachial plexus. In: Catterall A (ed). Recent Advances in Orthopaedics. Churchill Livingstone: Edinburgh, 1992, pp 65-76.

2 Rosson JW. Closed traction lesions of the brachial plexus-an epidemic among young motor cyclists. Injury 1988; 19: 4-6.

3 Narakas AO. Traumatic brachial plexus injuries. In: Lamb DW (ed). The Paralysed Hand. Churchill Livingstone: Edinburgh, 1987, pp 100-115.

4 Birch R. The brachial plexus. J Hand Surg 1992; 17B: 495-497.

5 Millesi $\mathrm{H}$. Brachial plexus injury in adults. In: Gelbermann $\mathrm{RH}$ (ed). Operative Nerve Repair and Reconstruction. Lippincott: Philadelphia, 1991, pp 1285-1328.

6 Bonney G. The value of axon responses in determining the site of lesion in traction lesions of the brachial plexus. Brain 1954; 77: $588-609$.

7 Marshall RW, de Silva RD. Computerized axial tomography in traction injuries of the brachial plexus. J Bone Joint Surg 1986; 68B: $734-738$.

8 Narakas AO. Neurotization in the treatment of brachial plexus injuries. In: Gelbermann RH (ed). Operative Nerve Repair and Reconstruction. Lippincott: Philadelphia, 1991, pp 1329-1358.

9 Sunderland S. Nerves and Nerve Injuries. 2nd edn. Churchill Livingstone: Edinburgh, 1978.

10 Loughlin SE, Fallon JF. Neurotrophic Factors. Academic Press: London, 1993.

11 Carrick MJ, Fullarton AC, Glasby MA. The tonic vibration reflex as a means of assessing proprioceptive function after nerve repair. A study in the rat. Neuro-orthopedics 1992; 13: 95-106.

12 Myles LM, Glasby MA. The fate of muscle spindles after various methods of nerve repair in the rat. Neuro-orthopedics 1992; 13: 15-23.

13 Banks RW, Barker D. Specificities of afferents reinnervating cat muscle spindles after nerve section. J Physiol 1989; 408: 345-372.

14 Barker D, Banks RW, Berry RB. Comparison of muscle-receptor recovery after nerve repairs using neural and non-neural grafts of two lengths. Neuro-orthopedics 1994; 14: 57-66.

15 Bonney G, Gilliatt RW. Sensory nerve conduction after traction lesion of the brachial plexus. Proc Coll Med 1958; 51: 365-367.

16 Kilvington B. An investigation on the regeneration of nerves with regard to the surgical treatment of certain paralyses. $B M J$ 1908; I: 1414-1419.

17 Glasby MA, Hems TEJ. Basil Kilvington, unknown pioneer of peripheral nerve repair. J Hand Surg 1993; 18B: 461-464.

18 Jamieson AM, Eames RA. Reimplantation of avulsed brachial plexus roots; an experimental study in dogs. Int J Microsurg 1980; 2: 75-80.

19 Glasby MA, Hems TEJ, Pell ACH. The use of coaxially aligned freeze-thawed muscle autografts in the repair of the cauda equina in the sheep. Acta Neurochirurgica 1992; 117: 210-214.

20 Hems TEJ, Glasby MA. Repair of cervical nerve roots; an experimental study. J Bone Joint Surg 1992; 74B: 918-922.

$21 \mathrm{Hems}$ TEJ, Clutton RW, Glasby MA. The repair of avulsed cervical nerve roots; a surgical model in the sheep. J Bone Joint Surg 1994; 76B: 818-823.

22 Carlstedt $\mathrm{T}$ et al. Regeneration after spinal nerve root injury. Restor Neurol Neurosci 1990; 1: 289-295.

23 Carlstedt T, Cullheim S, Risling M, Ullfhake B. Nerve fibre regeneration across the PNS-CNS interface at the root-spinal cord junction. Brain Res Bull 1989; 22: 93-102.

24 Carlstedt T. Experimental studies on surgical treatment of avulsed spinal nerve roots in brachial plexus injury. $J$ Hand Surg 1991; 16B: 477-482.

25 Anand P, Polak JM, Bloom SR. Aspects of neural and hormonal peptides. Clin Physiol 1985; 5: 110-120.

26 Sendtner M, Kreutzberg GW, Thonen H. Ciliary neurotrophic factor prevents the degeneration of motor axons after axotomy. Nature 1990; 345: 440-441.

27 Björklund A. Spinal cord repair-a question of making it work. Nature 1994; 367: 112-113.

28 Iwashita Y, Kawaguchi S, Murata M. Restoration of function by replacement of spinal cord segments in the rat. Nature 1994; 367: 167-170.

29 Schnell L et al. Neurotropin-3 enhances sprouting of corticospinal tract during development and after adult spinal cord lesion. Nature 1994; 367: 170-173. 